\section{Deaths from preventable adverse events originating in hospitals}

Drs Shojania and Dixon-Woods ${ }^{1}$ seem to misunderstand the nature of preventable adverse events originating in hospitals as characterised in my study from the Journal of Patient Safety (JPS) in $2013 .^{2}$ I do not appreciate being lumped in with the study by Makary and Daniel for their criticisms. ${ }^{3}$ In fact, I wrote a serious criticism on the Makary and Daniel study after it was published. ${ }^{4}$

Although Makary and Daniel started with almost the same data that I did, they deviated from the method I used and the conclusions I reached. My estimate, based on data available at the time of my review, asserted that approximately 400000 people die prematurely because of mistakes (preventable lethal events) originating during hospital care. I acknowledged that the deaths of these patients likely involved a basic cause, say cancer or cardiovascular disease, but a preventable adverse event initiated during hospitalisation brought on premature death from the core illness. I would not have asserted that medical errors alone were the third leading cause of death. It is in fact combined with other causes of death that led patients to be hospitalised in the first place. It is not an independent cause. As Shojania and Dixon-Woods note, 'it [is] very hard to allocate aliquots of blame to failures of medical management versus the patient's underlying illness'. ${ }^{1}$ To somewhat facilitate that allocation, herein I propose that a significant shortening of life (premature death) by medical mismanagement (ie, preventable adverse events) be defined as shown in the table 1 .

The types of preventable adverse events I estimated included the following: commission, omission, diagnostic, communication and context. These are all well-known types of preventable events or medical errors that lead to harm and death. I describe these in my JPS study. ${ }^{2}$ The deaths from preventable adverse events in the studies I used were mostly from hospital-acquired infections and medication errors.

In my JPS review, I looked at the adverse-event data from four studies and found them surprisingly in agreement given the different populations studied. I described why one would expect the variation observed, which was just over a factor of 2 . The estimate of preventability was a bit more complex. Preventability is subjective, depending on expert judgement of medical records that the harmful outcome could have been certainly or likely avoided. If the outcome was premature death then this is a lethal, preventable adverse event.

Makary and Daniel did not try to estimate adverse events that could not be detected by the global trigger tool (GTT) or were not evident in medical records. ${ }^{3}$ I did attempt that estimate, noting that the GTT is not good at detecting errors of omission, such as failure to follow evidence-based guidelines. Obviously, it cannot detect errors that are excluded from the medical record. I showed references in my JPS paper that this is surprisingly common, but the data are sparse.

My bottom line claim is this: in just over $1 \%$ of the 35 million hospitalisations in 2007, a preventable adverse event initiated during hospitalisation resulted in premature death. That premature death may have occurred during hospitalisation or it may have occurred months or even years after discharge. I gave an example of a massive error of omission ongoing in the early 2000s involving patients with heart failure who

Table 1 Proposed definition of premature death

\begin{tabular}{ll}
\hline $\begin{array}{l}\text { Life expectancy } \\
\text { of patient }\end{array}$ & $\begin{array}{l}\text { Life lost due to } \\
\text { medical management } \\
\text { failures (preventable } \\
\text { adverse events) }\end{array}$ \\
\hline$>3$ years & 1 or more years \\
$1-3$ years & 6 months \\
$<1$ year & 3 months \\
\hline
\end{tabular}

were not getting initial and sustained beta blocker treatment following a myocardial infarction. ${ }^{5} 6$ Beta blockers were shown to be lifesaving in a JAMA study published in $1982 .{ }^{7}$ These people died of heart failure but their death was premature because of the failure to prescribe beta blockers.

About 2.4 million Americans die each year. I assert that one-sixth of those die prematurely because of lethal, preventable adverse events initiated while hospitalised.

There is a need to get a consensus definition of medical error as it equates to preventable adverse events, both harmful and lethal. Furthermore, a consensus definition of what constitutes premature death from preventable adverse events needs to be developed. The National Academy of Medicine in the USA or an international body (WHO?) should undertake this effort.

\section{John T James}

Correspondence to Dr John T James, Patient Safety America, 14503 Windy Ridge, Houston, TX 77062, USA;

john.t.james@earthlink.net

Competing interests None declared.

Provenance and peer review Not commissioned; internally peer reviewed.

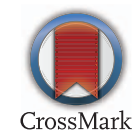

To cite James JT. BMJ Qual Saf 2017;26:692-693.

Received 25 November 2016

Accepted 4 January 2017

Published Online First 30 January 2017

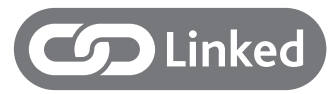

- http://dx.doi.org/10.1136/bmjqs-2016-006341

\section{REFERENCES}

1 Shojania KG, Dixon-Woods M. Estimating deaths due to medical error: the ongoing controversy and why it matters. BMJ Qual Saf. Published Online First: 12 Oct 2016. doi:10.1136/bmjqs-2016-006144

2 James JT. A new, evidence-based estimate of patient harms associated with hospital care. J Patient Saf 2013;9:122-8. 
3 Makary MA, Daniel M. Medical error-the third leading cause of death in the US. BMJ 2016;353:i2139.

4 James JT. Re: Medical error-the third leading cause of death in the US. A better way (letter). BMJ 2016;353: i2139. http://www.bmj.com/content/ 353/bmj.i2139/rr-49

5 Gheorghiade M, Gattis WA, O'Connor CM. Treatment gaps in the management of heart failure. Rev Cardiovascular Med 2002;3(Suppl 3):S11-19.
6 Lee TH. Eulogy for a quality measure. N Engl J Med 2007;357:1175-7.

7 A randomized trial of propranolol in patients with acute myocardial infarction. I. mortality results. JAMA 1982;247:1707-14. 